\title{
Building Partner Capacity Through Education: NATO Engagement with the Partnership for Peace
}

\author{
By James M. Keagle and Tiffany G. Petros*
}

Since the end of the Cold War, NATO has faced a different security environment than that which defined its mission for the first forty-plus years of its existence. As NATO seeks to redefine its role, it must consider newly emerging global threats such as terrorism, cyber attacks, and the proliferation of weapons of mass destruction that challenge both existing Alliance members and its global partners. It must also consider the nature of partnership itself, and the role NATO might play in building partner capacity to address global threats, participate in coalition operations, and enhance defense reform.

These themes - security and partnerships - are key to the NATO Lisbon Summit (held in November 2010) and the newly crafted NATO Strategic Concept. According to the recommendations of the Group of Experts on NATO's new strategic concept, "For NATO 2020, the twin imperative is assured security for all its members and dynamic engagement beyond the treaty area to minimize threats." ${ }^{1}$ U.S. Secretary of Defense Robert Gates sees building partner capacity as a critical element in promoting and sustaining security. In an article in the May-June 2010 issue of Foreign Affairs, Secretary Gates wrote, "[There] has not been enough attention paid to building the institutional capacity (such as defense ministries) or human capital (including leadership skills and attitudes) needed to sustain security over the long term."’2

* Dr. James M. Keagle received his Ph.D. from Princeton University, and served for over twenty-five years in the U.S. Air Force, and was wounded in combat. A teacher for over thirty years, he was provost at the National Defense University from 1999-2007. He coleads NATO's Defense Education Enhancement Program (DEEP) efforts in Georgia and Azerbaijan, and leads DEEP efforts in Montenegro. Dr. Tiffany G. Petros is a contractor supporting the Office of the Secretary of Defense (OSD) Partnership Strategy and Stability Operations. She has worked extensively in the PfP Partner countries and participated on DEEP teams in Azerbaijan and Montenegro. She previously served as a political science faculty member at Palacký University and the Anglo-American College in the Czech Republic, and as a visiting professor at the American University of Armenia in Yerevan. The views expressed in this article are those of the authors and do not necessarily reflect the official policy or position of any agency of the U.S. government.

$1 \quad$ NATO 2020: Assured Security; Dynamic Engagement: Analysis and Recommendations of the Group of Experts on a New Strategic Concept for NATO (Brussels: NATO, 17 May 2010), 12.

2 Robert M. Gates, "Helping Others Defend Themselves: The Future of U.S. Security Assistance," Foreign Affairs (May/June 2010): 4. 
One way in which the United States, its NATO Allies, and Partnership for Peace (PfP) Partners are cooperating to enhance security through building defense institutions and developing human capital is in the context of Professional Military and Civilian Defense Education. There is a common recognition that it is not enough to ensure that Partner-Alliance weapons systems are interoperable to promote security; rather, shifts in mindset and enhancements in institutions are also required.

This article will explore innovative initiatives NATO_-both collectively and as individual members and partner nations-is taking to support PfP Partners in building partner capacity in the area of education. It will also present a case for why these initiatives are so important: from building reliable partners, to deterring conflict in Europe and Eurasia (e.g., frozen conflicts in the South Caucasus), to strengthening Partner nations from within. It will demonstrate a link between the complex security issues facing the Alliance and the role of education and training in transforming both individuals and societies. Education and training transformation is a high-priority mission that will need to be sustained for decades in order to contribute to more reasoned decisions, better leadership, and ultimately a region at peace.

\section{NATO's Partnership for Peace}

NATO launched the Partnership for Peace in 1994 as a means of promoting reforms, increasing stability, and enhancing security relationships both between and among Partner countries and NATO. ${ }^{3}$ PfP provides a forum for Partners to tailor their relationships with NATO, agree on common activities, and implement them at a level and pace that is acceptable to each government.

In this way, the Partners "self-differentiate" their levels of cooperation with the Alliance. ${ }^{4}$

Although several non-aligned, developed Partners joined PfP (e.g., Austria and Switzerland), the majority of the new PfP countries were former Communist states from the Warsaw Pact. Thus, NATO viewed new avenues for cooperation as an important aspect of changing mindsets, such as encouraging support for democracy, as well as enhancing security through increased military interoperability.

3 There are currently twenty-two PfP members: Armenia, Austria, Azerbaijan, Belarus, Bosnia and Herzegovina, Finland, Georgia, Ireland, Kazakhstan, Kyrgyz Republic, the former Yugoslav Republic of Macedonia, Malta, Moldova, Montenegro, Russia, Serbia, Sweden, Switzerland, Tajikistan, Turkmenistan, Ukraine, and Uzbekistan.

4 Building on the success of PfP, NATO has introduced other regional partnership frameworks to enhance cooperation (e.g., the Mediterranean Dialogue to support cooperation between NATO and North African countries, and the Istanbul Cooperation Initiative to support cooperation with countries of the broader Middle East). NATO has also established the NATO-Russia Council, the NATO-Ukraine Commission, and the NATO-Georgia Commission to facilitate direct cooperation between these countries and the Alliance. 
Since PfP was established, twelve former members have joined the Alliance. ${ }^{5}$ NATO enlargement has replaced the traditional orientation toward containment of the Soviet Union and Russia as the Alliance's principal policy direction. ${ }^{6}$ As NATO has welcomed Allies from Central and Eastern Europe, PfP efforts and activities have been increasingly focused on countries farther to the east. At the Istanbul Summit in 2004, NATO heads of state and government agreed, "In enhancing the Euro-Atlantic Partnership, we will put special focus on engaging with our Partners in the strategically important regions of the [South] Caucasus and Central Asia."7 To that end, NATO appointed a Special Representative to the South Caucasus and Central Asia as well as two NATO Liaison Officers, one to each region.

NATO's enhanced focus on Central Asia and the South Caucasus has been coupled with increased attention to education and training of PfP Partners. Since 2007, NATO (and in some cases the United States bilaterally) has conducted Defense Education Enhancement Programs (DEEPs) with Armenia, Azerbaijan, Georgia, Kazakhstan, Moldova, and Montenegro. The Partnership for Peace Consortium of Defense Academies and Security Institutes (PfPC) has played a leading role in bringing together Allies and Partners to develop and execute DEEPs. ${ }^{8}$ These programs, which are tailored to meet individual Partner requirements, provide opportunities for the PfP Partners to develop both their defense education curricula and faculty. Not only do these programs provide an effective way to transform national security establishments and enhance the security capabilities of Partners, they also do so in a way that does not provoke neighboring nations. In the case of the South Caucasus, it may be the best means to avoid the region becoming a "shatter zone" along the rim land, and "marginal areas" to Mackinder's pivot and heartland thesis-a prominent line of thought in NATO as it wrestles with security challenges and opportunities in the region. ${ }^{9}$

5 Former PfP Partners turned NATO Allies include Albania, Bulgaria, Croatia, Czech Republic, Estonia, Hungary, Latvia, Lithuania, Poland, Romania, Slovakia, and Slovenia.

6 See, for example, Ronald Asmus, Opening NATO's Door (New York: Columbia University Press, 2002), for a balanced discussion of NATO's enlargement efforts in the post-Cold War era.

7 NATO, "Istanbul Summit Communiqué," 28 June 2004.

8 For more information, see http://www.pfpconsortium.org.

9 See, for example, Robert D. Kaplan, "The Revenge of Geography," Foreign Policy (May/ June 2009): 96-105). 


\section{The Road to NATO Membership: The Role of NATO Tools in Enhancing Cooperation}

NATO PfP Partners of today find themselves cooperating with a different type of NATO and using different NATO tools to tailor their cooperation with the Alliance than did early Partners turned Allies (e.g., the Czech Republic, Hungary, and Poland in 1999). Today's Partners fall along a spectrum. Some have expressly stated their desire for future membership in the Alliance (Georgia), while others have a desire to cooperate with NATO, but also want to balance their relationship with Russia and other countries to the East (Armenia and Kazakhstan). Still other countries have changed their position with respect to NATO, given changes in their internal politics (Ukraine). NATO welcomes this diversity in its cooperative relationships, and has developed a range of tools to assist Partners in shaping the type of cooperation and activities that these nations wish to pursue.

The Individual Partnership Program (IPP) provides the foundation for cooperation between the Partner nation and NATO and is agreed upon and renewed on a two-year basis. All PfP Partners have developed IPPs with NATO. The IPP allows the Partner to identify areas for cooperation with NATO as drawn from the Euro-Atlantic Partnership Work Plan (EAPWP). The Individual Partnership Action Plan (IPAP) goes a step beyond the IPP and is designed for Partners who are interested in an enhanced dialogue with NATO. Kazakhstan is currently the only Central Asian state to have an IPAP with NATO. Armenia, Azerbaijan, and Moldova also have IPAPs. The Membership Action Plan (MAP) is the next phase of cooperation. It is the primary tool used to prepare Partners for the responsibilities of NATO membership. Unlike IPAP, where countries identify areas that they want to address with the Alliance, MAP provides the Partner with a range of NATO requirements. The Former Yugoslav Republic of Macedonia (FYROM) and Montenegro currently have MAPs. Finally, Annual National Programs (ANPs) have been established with Georgia and Ukraine to indicate a level of cooperation with NATO that is beyond IPAP, but that proceeds on a different path from MAP.

Regardless of what path a PfP Partner chooses, the path to closer cooperation with NATO involves transforming both public and private sectors in order to promote democracy, good governance, the rule of law, and sustainable social and economic development. Beyond these goals, specific reforms of the security sector-in particular the revision of a Partner's national security plans and development of their IPAPs, MAPs, and ANPs - require that the Ministries of Defense (MoDs) understand that traditional defense functions are no longer their sole responsibility. In fact, MoD missions in the twenty-first century are just as likely to include all of the above in addition to the long-standing functions of deterring war, and fighting and winning war, should deterrence fail. 
A particular challenge is how to prepare the national security professional for these new missions. No single skill set applies uniformly to the diverse set of missions in which the armed forces and its individual soldiers, sailors, and airmen are likely to be engaged. Law enforcement, stability operations, peace support operations, reconstruction, and the use of deadly force are part of the landscape of these new missions. Moreover, the mission requirements of these likely actions may change when the units and individuals turn the corner, quite literally. In light of this reality, both NATO and the United States have placed education at the top of the list of transformational priorities. According to the 2010 U.S. Quadrennial Defense Review (QDR), "DoD will place special emphasis on ... building partner capacity skill sets in its professional military education and career development policies." ${ }^{10}$ Changing how people think, how they approach problems and analyze and evaluate courses of action, and how they implement their assignments will pose considerable challenges to the armed forces for the foreseeable future. PfP Partners also recognize the need for education and training to address a wide range of security challenges. As such, Partners from across the Balkans, Central Asia, Eurasia, and the South Caucasus have raised education and training transformation to one of the highest priorities in their agreed NATO IPAPs, MAPs, and ANPs.

\section{Building Partner Capacity: Education as a Key to Security Sector Re- form}

The majority of NATO's PfP Partners are emerging from legacy systems in which decisions were made at the top and executed at the bottom, with little opportunity for discussion or input in between. Information was provided on a need-to-know basis, and interagency cooperation was not necessarily part of the decision-making process. Long-standing bureaucracies continue to shape interactions between individuals and organizations throughout much of Eurasia. However, in order to meet today's challenges, there is a greater demand for effective integration of all instruments of power-military, political, economic, and informational-by multiple agencies of the security establishment rather than the singular application of a particular instrument by a single organization. This is true not only for PfP Partners, but also for the United States and other NATO Allies, all of whom struggle with how to make the interagency process more effective, transparent, and useful.

10 U.S. Department of Defense Quadrennial Defense Review (Washington, D.C.: U.S. Department of Defense, 12 February 2010), 54. 
Even though almost all the results that national governments strive to achieve require the concerted and coordinated efforts of multiple agencies, linear thinking and parochialism dominate. Blaming others is more common than accepting shared responsibility and sharing resources. Worse, few incentives exist to collaborate. In fact, barriers to and punishment for such sharing and collaboration are more often the norm.

What is needed is a means to break down these closed, hierarchical, self-interested, and stove-piped systems in favor of systems and processes that can transcend organizational and personal boundaries to achieve effective cooperation. Such a philosophy rests upon the following principles:

- No one organization can successfully provide the required resources, autho-rity, and expertise

- Matrixed, networked organizations are the goal

- Cultural change must precede systemic reform

- Changing people (and the way they think) is the key to changing organizations.

This new paradigm first and foremost demands investment in education, in changing the way people think. Most importantly, that entails new curricula, different faculty and student bodies, and teaching methodologies based on active learning, in order to expand the next generation of leaders' peripheral vision. Equally important, there needs to be a transformation in the academic setting, with a classroom experience that replicates the interactions that will take place in the new security environment. That means that classrooms should include diverse personal and organizational perspectives from those who represent the entire national security establishment: army, navy, air force; ministries of defense, foreign affairs, commerce, interior, justice, etc.; and our Allies and coalition partners. These kinds of student bodies will enrich dialogue and discussion, all while encouraging the critical thinking that is so essential to addressing the challenges of today. 
THE QuARTERLY Journal

\section{The New National Security Professional}

As NATO Allies and PfP Partners work together to build defense institutions and develop human capital, programs need to be put in place to educate national security professionals in new ways and produce graduates with different skill sets. They need to be able to:

- Think strategically (not just operationally or tactically), critically, and creatively

- Lead interagency teams

- Collaborate and persuade, not just "command"

- Plan and manage interagency operations

- Possess global and cultural acuity

- Communicate (not just issue orders).

The aim is to develop national security professionals who, in the dimensions below, shift their intellectual balances in the direction of the left-side characteristics:

\section{Cognitive}

\begin{tabular}{lcl}
\hline Culturally Intuitive & vs. & Technically Proficient \\
Identify Patterns & vs. & Identify Issues \\
Think Globally & vs. & Think Parochially \\
Imagine & vs. & Assess \\
Operate Across Disciplines & vs. & Operate in Single Core Competencies \\
& Judgment & \\
\hline Question Assumptions & vs. & Accept Judgment \\
Take Calculated Risks & vs. & Avoid Risk \\
& Technical & \\
\hline
\end{tabular}

Shape Technology vs. Accept Technology

\section{Communications}

\begin{tabular}{lll}
\hline Interaction Oriented & vs. & Computer Oriented \\
Networked & vs. & Insular \\
Real-Time Collaborators & vs. & Report Reliant \\
Story Tellers & vs. & Explainers \\
Scenario Writers & vs. & Report Writers \\
Context Presenter & vs. & Occurrences Presenter
\end{tabular}

\begin{tabular}{lcl} 
& \multicolumn{2}{c}{ Role } \\
\hline Anticipatory, Proactive & vs. & Responsive, Reactive \\
Customer Focused & vs. & Role Focused \\
Outcome Oriented & vs. & Product Oriented $^{11}$
\end{tabular}

11 Information formally presented by Ms. Platz-Vieno in a PowerPoint brief at the National Defense University (NDU) on 23 February 2009 
This is the domain of education and training. It is what is motivating NATO to shift its attention from weapons systems to joint, multinational, and interagency education and training of those people who more broadly develop and employ the doctrines, strategies, and policies that integrate all the instruments of power-political, military, economic and informational - to produce leaders better equipped to deal with a range of issues that define the twenty-first-century security environment: "smart power." ${ }^{12}$ Misinformation and miscalculation can lead to poor leadership and decision making — and to war, death, and destruction. Limiting those outcomes is what national security education and training transformation is all about. It will require different kinds of faculty, different kinds of curricula, and different approaches to teaching. Moreover, it will require patience, for none of these transformations will occur overnight.

\section{The NATO Response: The Process Operationalized}

As developing PfP Partners look to better understand Western "ways of thinking" and develop their own national security professionals, they have turned to NATO Allies and other Partners for Professional Military Education (PME) support. Countries from the Balkans, Central Asia, South Caucasus, and Eurasia are all engaged in discussions with NATO on PME topics of interest through both bilateral and multilateral DEEPs. ${ }^{13}$ PfPC has played a particularly important role in facilitating this engagement. The DEEP approach, as described below, provides an alternative to sending Partner officers, NCOs, and civilians to courses abroad, and thus makes defense education more accessible to a larger number of participants.

12 See U.S. Secretary of State Hillary Clinton, testimony to the U.S. Senate, Appropriations Committee, Washington, DC, 30 April 2009

13 The DEEP initiative began in 2007 with a program in Kazakhstan (NATO-U.S. co-leads) and has since expanded to include countries in the South Caucasus and Balkan region. Current DEEP programs include Afghanistan (NATO lead); Armenia (NATO-Canadian co-leads); Azerbaijan (NATO-U.S. co-leads); Georgia (NATO-U.S. co-leads); Moldova (NATO-U.S. co-leads); and Montenegro (U.S. lead). It is important to note that other Allies and Partners are contributing both to the DEEP teams and to a range of other PME activities to support PfP Partners that are outside the scope of the DEEP projects. Efforts are being made to de-conflict all relevant projects while providing the Partners with necessary subject-matter expertise. 
Since DEEPs are tailored to meet individual Partner needs, they also provide PfP members with the opportunity to self-differentiate in both their assistance requests and in the level of cooperation they desire with NATO on PME issues. DEEP initiatives to date have responded to a variety of requests for assistance, including developing course modules, establishing a Command and General Staff College, starting up research institutions, and offering faculty "shadow" programs, to name a few.

In order to establish a DEEP between a Partner and NATO (or an individual ally nation, if the DEEP is bilateral), NATO (or the ally) sends a visiting team of subjectmatter experts to the Partner country for approximately one week to discuss Partner needs, priorities, and objectives for future education reform. These Curriculum and Teaching Development Teams (CTDTs) (of three to five persons) are composed of subject-matter experts who are both academics (teachers) and practitioners with recent field experience, as well as those who are knowledgeable on the countries and their sensitivities. On their side, the Partner country identifies future instructors, heads of existing military institutes/training departments, and others involved in education reform who will be instrumental to the change process. The Partner also provides opportunities to meet with political and military leadership in order to ensure that support for education reform is gained and maintained at the highest levels. By including education and training as a priority in their NATO documents (IPAP, ANP, or MAP), the Partner state also signals to NATO the importance they are placing on reform in this functional area.

Once a baseline is set and an Action Plan has been agreed upon between NATO and the Partner (or bilaterally), the CTDT makes repeat visits to the country to assist with both curricula and faculty development as needed. In some cases, this means that the team co-teaches courses for a couple of days with the host-nation instructor to provide a practical component to the theoretical discussions on methodology, syllabus development, etc. Over time, the CTDT recedes to the background while the host nation assumes the primary role. The CTDT remains ready to assist or provide additional information on an as needed basis. 


\section{Implementation}

Depending on a country's needs and the availability of Allies and NATO to support program implementation, the CTDT teams may be conducted on a multinational or bilateral basis. A NATO representative may also be involved in crafting the Action Plan (in accordance with other NATO agreements, such as IPAPs) and/or the NATO Liaison Officer (LO) in the region (in the case of the South Caucasus and Central Asia) may play a role. The NATO LO may be active in crafting the plan, executing the CTDT, and consulting with the Partner between visits to ensure that the process is moving forward as scheduled. To ensure support from all sides, the DEEP PME Action Plans are also briefed at NATO Headquarters in the Political and Partnerships Committee (PPC) (formerly the Political-Military Steering Committee).

\section{Review and Assessment Session}

At the beginning of each year and following the approval of an Action Plan, a select team of NATO experts and their counterparts from the Partner MoD should conduct a review and assessment. The objectives of this session are to assess the effectiveness of the program and complete the coordination for the events scheduled for the upcoming year and beyond. The pace and intensity of this Action Plan can be adjusted to reflect the needs of the host nation. Priorities should be reaffirmed and additional requirements should be identified.

\section{End State}

The desired end state of these PME Action Plans is to meet the educational objectives of the host nation as specified in their Membership Action Plans, Annual National Programs, or Individual Partnership Action Plans. As such, it is focused on institutional enhancements, curricula development, adoption of NATO standards, and faculty development and education. Implementation of this Action Plan should result in the establishment of a Professional Military Education program that will prepare officers and NCOs for complex and interagency operations and represents intellectual interoperability between NATO and PfP Partners. Executing the events suggested in this plan will also contribute to strengthening the cooperative relationships between NATO and the host nation.

Although existing education programs between NATO and PfP Partners primarily focus on Professional Military Education, there is also a recognized need for Civilian Defense Official Professional Education. Many PfP Partners are just now introducing 
civilian employees into their MoDs and beginning to work with think tanks and institutes that rely on civilian defense expertise. The education of civilians will thus take on an ever more important role in developing national security professionals.

In addition to educating civilians, the DEEPs have worked with PfP Partners to consider how to make more effective use of their existing civilian universities to support the development of military and civilian defense officials. Programs at civilian universities - including politics, humanities, finance, etc.-have relevance to defense curricula, and could play an important role in supporting defense education.

\section{Curricular Challenges}

As NATO and Partner nations work together to rethink their defense curricula and make changes that will increase intellectual interoperability, there are a number of areas that should be considered. This is particularly true since curricula intersect and interact with several other aspects of a country's military system, from strategy and doctrine to the development and implementation of human resource management systems to how lessons learned from military operations are captured and integrated to ensure continuously enhanced preparation and improved execution.

In order to better understand the role education plays in the larger military framework and the various aspects of curricula that need to be considered, the following areas should be highlighted:

- Doctrine and defense planning education and training. Doctrine is at the core of any national security establishment, and how to incorporate its fundamental principles into the education and training systems is a requirement of the first order. It is the central document that guides force structure and its management. From that will flow all serious programs in defense planning, be they based on SWOT (strengths, weaknesses, opportunities, threats) analysis; courses of action analysis; ends, ways, and means analysis; or other models. While often understood as strategic in nature, education and training programs in doctrine and defense planning need to be melded into curricula at the tactical and operational levels as well.

- Personnel management system integrated with professional military education and training and force management. It is essential that a personnel management system be married to the education and training transformation efforts. This is all about ensuring that the right individuals get the right education and training at the right times in their careers. This means careful coordination of pre- and post-education assignments, rigorous processes for student selection, and proper attention to promotions for both faculty and students. Both student and faculty assignments must be perceived as career-rewarding, not career-threatening 
or career-ending. The legislative branch may be required to actively oversee these personnel functions to ensure that operational pressures do not override the need to invest in education and sustain that investment over the long term.

- Cradle-to-grave curriculum review and transformation throughout the education and training system. Specific emphasis in curriculum review needs to be placed on the operational and strategic levels; tactical level emphasis, while important, needs to be balanced with education and training at the operational and strategic levels. Additional focus is needed on command and control, integration of the air-land battle, air defense support, and logistics/supply chain management. Education early in one's career should be focused on developing specific core competencies and is principally conducted in a service-specific or organizationspecific environment. Over time, the individual needs to be educated in a more balanced joint, multinational, and interagency academic setting.

- NCO education. Special attention needs to be paid to the non-commissioned officer (NCO) force. Increasingly, the leadership and decision-making roles of the NCO are crucial to success on the battlefield. For several PfP Partners, developing and changing the manner in which NCOs are utilized will be particularly important to the transformation of their armed forces. While many different approaches to NCO education and training exist in NATO, they all share one common feature: each recognizes the value of NCOs in the leadership and management of the force, and educates and trains the NCOs to perform these leadership and management functions. The direct involvement of the Allied Command Transformation (ACT) Command Sergeant Major has been instrumental in the early successes of the NATO/DEEP teams.

- Pre-commissioning programs. It is essential to invest early in the development of the next generation of leaders. While four-year models may not be an affordable answer either in time or money for every country, certainly multi-year programs are in order to provide the intellectual foundations upon which to build the future security leadership. Investing early to build solid foundations will yield significant benefits over the course of one's career.

- Junior officer education. Continuing with the theme above, early investment in military education systems for lieutenants is paramount to develop the core competencies necessary for tactical, operational, and strategic level joint, combined, and interagency missions. Time is the critical variable, and each country is under different kinds of pressures to shrink the investment in education and get their new crop of officers into the field. These impulses need to be balanced against the need 
to educate and train their officers more fully, so that they understand their core competencies and can represent them effectively in the security environments in which they are likely to operate.

- Mid-level officer education. Mid-level education for senior captains and majors is the place to truly emphasize the shift from service-specific core competencies to the joint environment. Multi-service operations are increasingly the norm. Education that mixes a curriculum specializing in joint operational content with a joint classroom environment will build the kinds of expertise, institutional understanding, and personal levels of trust to produce more effective security strategies and problem solving.

- Senior officer education. Focused in war studies, decision making, defense management, rule of law, ethics, the geo-political context, and leadership, PfP countries need to consider up to one-year-long programs for their lieutenant colonels and colonels. As valuable as they are in the field, it is even more important now to create the appropriate academic environments for senior officials so that they can test their ideas and expand their peripheral vision in concert with those with whom they will likely interact in their next assignments.

- General officer education. At the general officer level, the emphasis truly shifts to leadership and decision making with senior civilian defense officials and in coalition and interagency environments. Courses of several weeks up to two months long are the appropriate length to consider.

- Logistics. Connecting logistics curricula to the ongoing NATO Logistics Exercises is important for nations developing their deployable niche capabilities. It will demonstrate the linkages between and among tactical, operational, and strategic logistics issues.

- Effective means for education and training in joint, combined, interagency, and ultimately coalition operations. This is likely to require Command Post Exercises and other simulation experiences to prepare the armed forces at all levels for the kinds of operational experiences that will define their careers in the twenty-first century.

- Lessons learned system. It is critical that experiences from the battlefield be quickly captured, studied, and incorporated into educational curricula. This implies an active role for unit historians, oral histories, joint war fighting centers, and dynamic schoolhouses and training centers that can take the lessons learned from the battlefields and incorporate them into curricula and lesson plans. 
- Language education. This is a high priority. Immersion education should be the first choice over part-time language opportunities. There is also a need for a course in military terminology. Several years of assistance visits in the region by NATO's Bureau for International Language Coordination (BILC) expert teams support this analysis, and any future efforts should be coordinated with the BILC. The issue of language education highlights the important relationship between education and training and personnel management systems. There are different requirements for different members of the armed forces at different times in their careers. Shaping this requirement and matching the right individuals with the right assignments with the right capabilities at the right time is a central challenge for both education and training and personnel systems. As a foundational skill, this suggests closer coordination with ministries of education for the establishment of language education throughout society. This closer relationship could benefit the MoDs should they seek academic accreditation for their courses. English language education is essential.

\section{Faculty Challenges}

Like curriculum development, faculty development is key to transforming PME systems in PfP Partner countries. The development of human capital is crucial to the success of individual Partner PME Action Plans, and more importantly to the ability to sustain transformation. Some key faculty challenges are as follows:

- Develop teaching skills for existing and new curricula, as well as processes for curriculum development, review, and refinement. Lectures, while having a place in education, need to give way more often to an active learning environment consisting of seminar and small group discussions, exercises, and simulations. Drawing on the experiences of the students is important. At the undergraduate level, classroom time needs to be limited to twenty to twenty-five hours per week. At the graduate level, classroom hours should be held in the range of twelve to twenty hours per week. Classic military principles need to be made relevant for the twenty-first-century security environment. Use of new technologies, including distributed learning techniques, need to be merged into the curricula so that the proper balance between in-classroom and out-of-classroom education can be realized. Faculty should have a mix of operational experience and academic credentials. Most importantly, they need to be able to inspire students to think critically, challenging their own assumptions and accepted dogmas. This may be the single most important - and difficult_challenge faced by educators. Processes for changing curricular content - immediate "hot washes" and more systematic reviewsare essential to keep curricula relevant and on pace with the rapidly changing 
security environment. A novel approach that has emerged as part of DEEP initiatives is a "shadow" faculty program. The U.S. Naval War College became the first host of such a program in 2011. The idea here is that select Partner nations send select faculty to a U.S. PME institution for several weeks, to live first-hand the life of a faculty - e.g., participating in faculty meetings where colleagues discuss curricula, methodologies, and individual approaches to lessons; in actual seminars; and in post-seminar and course reviews, among other activities.

- Establish a personnel management system that provides incentives for faculty duty. Essential to meeting this challenge is building and maintaining a faculty that has the right balance of academic credentials, teaching experience, and operational experience. This includes keeping long-serving faculty current through operational and academic sabbaticals and having faculty duty be viewed as career-enhancing, with the proper promotional and assignment opportunities for those faculty who depart after a tour of faculty duty. This commitment to a core faculty (ideally for at least three to five years) is essential to the stability needed to oversee education transformation. Normal annual faculty turnover should be about 20 to 25 percent. This will help new ideas and fresh approaches be introduced in the classroom and avoid one of the greatest dangers that can inflict a faculty: complacency. Partnering with civilian academic institutions should also be considered.

- Establish an MoD program for the recruitment, training, and professional development of MoD civil servants. The growth and nurturing of a civilian cadre of defense officials is an urgent need for all the countries of the region. This will help strengthen the commitment to civilian control of the armed forces and the apolitical role of the military in society. Mixing their education and professional development with those of the armed forces will again contribute to building personal relationships between and among the military and civilian security officers. In many ways, the curriculum becomes a prop to bring the officials together to explore the difficult questions from the range of vantage points afforded by the mixed student body. Faculty must understand the value of this environment. Faculty composition, too, should mirror the composition of the student body in representing all the agencies of the security establishments. 


\section{Student Body Size and Composition Challenges}

Selection of students and the ability to retain students after graduation is key to the success of PME reform in PfP countries. For students wishing to participate in education programs abroad, language ability will also be key. Below are some issues to consider in selecting students and determining student body composition:

- Develop a rigorous and open process based on merit for the selection of the students to attend various PME programs. This entails transparency in selection criteria, and should ensure balanced representation across the national security establishment, particularly for the higher-level programs. Each organization should build its own processes for student selection and publicize the criteria for selection.

- Ensure proper assignments and utilization for students upon graduation. This reinforces the concept of the right education for the right student at the right point in his/her career. It also makes education in the classroom easier, as it should contribute to a common knowledge base and set of professional experiences with which all students enter the program. Tracking alumni and commanders in the field with post-course, longitudinal studies to determine the effectiveness and relevance of their education and training experiences is a must.

- Balance formal academic programs with other social and athletic elements to build trust and relationships between and among the students. It is essential to create and promote non-academic settings for the development of trust-based relationships and friendships between and among the students. These relationships will carry forward beyond the completion of a specific program and can contribute to problem resolution in the field.

- Create sufficient time outside of the formal classroom activities for critical thinking and reflection. Programs must structure themselves to allow deeper analysis and evaluation and synthesis of the themes of the courses. One rule to follow is to strive for a two-thirds to one-third balance. Up to two-thirds of academic time should be spent in the higher-order intellectual functions of Bloom's taxonomy. Honing the ability to think through complex issues and organize one's thinking into a tight package is highly valued in the business of national security.

- Construct adequate educational facilities, including billeting. This also means that sufficient funds must be dedicated for proper informational and educational technology infrastructures (computers, Internet access, email, etc.). Careful deliberations must precede construction, and equally prudent decision making must 
THE QuARTERLY JOURNAL

accompany equipment procurement. Not only are there costs to teach the faculty how to use the equipment effectively, there are also significant costs in maintaining increasingly high technology equipment, as well as in providing the right physical environment for security and information assurance.

\section{Summary and Conclusions}

Education and training transformation across the Partnership for Peace countries is intended to contribute to peace and security in the Euro-Atlantic region and beyond. It may ultimately prove to be key to strengthening defense institutions, enhancing capabilities to support coalition operations and respond to global threats, and possibly even unfreezing existing regional conflicts. In addition, it will help to develop individuals with new ways of thinking, a willingness to work across agencies to improve decision making, and an interest in supporting reforms and training a new cadre of defense professionals to do the same.

The willingness of PfP states to consider DEEPs as an innovative approach to defense education reform is an important first step. It is understood by NATO that reforms will not always be quick or easy. However, by working with the Alliance, Partner nations can benefit from a range of perspectives and subject-matter expertise that may not be otherwise be available to them. For example, DEEP offers PfP nations the opportunity to hear from former Partners turned Allies regarding the lessons they have learned. Romania, for one, has played an important role on DEEP teams by offering to share its recent experiences. Also, as a PfP participant, Romania received the support of a Curriculum and Teaching Development Team (CTDT) in the area of defense resource management and subsequently developed a program that later expanded to include Partners in Southeast Europe. This is only one such success story, but it demonstrates that small steps and committed individuals can ultimately bring about big change.

Finally, the priority NATO has placed on the topic of professional and civilian military education can also be seen through its commitment to the development of reference curricula to be shared with Partners. A Partnership Action Plan on Defense Institution Building (PAP-DIB) Reference Curriculum has already been published, and a Generic PME Curriculum is being finalized. These publications offer a resource to those who are working to develop programs consistent with Western standards. NATO has also stressed the value of using Western learning methods based on active learning models, student-centered versus teacher-centered instruction, and critical thinking to boost absorption of curriculum content. Partners are increasingly adopting these methods. PfP nations and current Allies should use all of the resources available to them to build Partner capacity and enhance human capital. It is through 
our shared contributions and collective action that we will meet the new challenges of the twenty-first century. Building a self-sustaining educational foundation, not just operational capacity, may be the critical cornerstone to building lasting security policies_-and enduring peace. 
THE QUARTERLY JOURNAL

\section{Bibliography}

Gates, Robert M.. "Helping Others Defend Themselves: The Future of U.S. Security Assistance." Foreign Affairs (2010).

Kaplan, Robert D.. "The Revenge of Geography." Foreign Policy (2009): 96-105. 